\title{
Literacies and effective learning and teaching for all
}

In the proceedings of the IAIMTE conference, which took place in Paris in June 2013, we are particularly interested in issues of teaching and learning in relation with literacy. The achievement of students assessed on an international basis (PISA for fifteen years old students, PIRLS for primary school students in their fourth year at school) have got the attention of managers, teachers and researchers on two major issues:

- the difference among systems and practices when effectiveness in improving literacy is concerned, as far as improving the literacy skills of students is concerned;

- the differences among systems and practices when equity is concerned: in some cases, the gap between pupils may deepen, while in other cases, teaching practices may boost skilled pupils as well as underachievers.

These inquiries also shed light on the various ways of determining effectiveness and equity in teaching practices from one country to another.

We especially focus on effective teaching and learning, on attainment levels, on what students, teachers, schools and the educational system as a whole must achieve.

So the authors of articles below have questioned the ways of teaching and learning:

- How to read, how to write and how to speak along with the impact of literacy in school subjects as far as effectiveness and equity are concerned?

- Which discrepancy is likely to be seen between achievements expected from students at each stage of their schooling and what is actually taught?

- How do teachers/does education support students of different capabilities to reach the goals stated in curricula?

These researchers have dealt with any school level (primary, secondary schools and higher education), with teachers' education. They have drawn from any discipline able to throw light on how to build literacy skills: linguistics, philosophy, sociology, literature. The focus is on teaching practices, even on professional skills of teachers, or on how students deal with their learning tasks and the reasons why they fail or succeed.

These themes are explored in the different articles:

- Evaluation

$\circ$ Which evaluation of literacy?

- What are the levels of literacy for various groups of students and how are they evaluated?

- Which explicit aims are given to teaching literacy?

- Equity, differentiation and effectiveness

- Which correlation may appear between social inequalities in habits in literacy and school consequences?

- What are good practices of cross fertilization between spoken and written language as far as learning literacy skills is concerned?

- How to read, speak, write in the various school subjects and academic disciplines? 